\title{
Comments on: \\ A flow balance approach to scenarios for water reclamation by Ania MW Grobicki and B Cohen
}

I would like to offer a brief comment on the above paper, which appeared in Water SA 25 (4), October 1999.

Reuse of treated sewage effluent is essential to the survival of this country and this paper correctly highlights that this important resource is not being optimally used.

I am concerned though that the research undertaken by the authors might not be correct in that return flows from water reclamation plants on river systems where there are dams downstream do not appear to have been considered.

An actual case study is the Systems Analysis for the Amatola Region where the assured yield of the Bridal Drift Dam without and with allowance for return flows from King William's Town, Bisho and other point sources was around $40 \mathrm{Ml} / \mathrm{d}$ and $55 \mathrm{Ml} / \mathrm{d}$ respectively. I am not sure of the actual figures but they are available from the Department of Water Affairs (The actual figures are available from the Amatola Water Board - Editor).

The scenario repeats itself in many other river systems such as the Umgeni and Vaal to name but two.

\section{Dave Horne}

Director: Support Services

University of Port Elizabeth

The following reaction was received from the co-author, Dr Brett Cohen:

This is a somewhat belated reply to a letter sent to Dr Grobicki in May 2000 (your ref K3/6/1223), regarding our paper entitled A Flow Balance Approach to Scenarios for Water Reclamation, published in Water SA 25 (4), October 1999, and the comment received regarding this paper from David Horne of UPE.

Mr Horne raises a valid point regarding the existence of scenarios for impacts of reclaimed water usage other than those raised in our original paper. Due to time limitations within the study on which this paper was based, it was only possible to consider a narrow range of scenarios. A proposal was recently submitted to the WRC for an expansion of the scope of this project to encompass all possible scenarios, and how reclaimed water usage impacts on river and dam flows, levels, water qualities and ecosystems. Unfortunately the funding for this project has not been approved. We do hope to further persue this work in the future, and will most certainly raise Mr Horne's issues within this context.

\section{Dr Brett Cohen}

SRK Consulting 